\title{
Historia de la pocomía en Limón (Costa Rica) y Bocas del Toro (Panamá). De finales del siglo XIX a la actualidad
}

\author{
The History of Pocomia in Limon (Costa Rica) and Bocas \\ del Toro (Panama). From Late Nineteenth Century to the \\ Present
}

\begin{abstract}
Axel Alvarado Luna
Profesor de historia e investigador de la Sede del Caribe, Universidad de Costa Rica. Maestría en Historia por la Universidad de Rusia de la Amistad de los Pueblos, 1998. Correo electrónico: axelalvarado2614@gmail.com
\end{abstract}

DOI: http://dx.doi.org/10.15517/rehmlac.v8i2.23577

Fecha de recibido: 16 de octubre de 2015 - Fecha de aceptación: 20 de noviembre de 2016

Palabras clave

Pocomía; fraternidad; cultura; religión; mito

Keywords

Pocomia; fraternity; culture; religión; myth

\section{Resumen}

La historia de la ciudad de Limón es totalmente diferente a la historia de Costa Rica. Su origen cultural, económico, étnico y hasta urbanístico marcan una diferencia tan grande que incluso se podría hablar de un país dentro de otro país. Una de las causas que marcaron esa diferencia fue la construcción de un verdadero mega proyecto, nos referimos al ferrocarril que uniría la capital con el Caribe. Trabajaron en la construcción italianos, chinos, centroamericanos, coolies de la India, negros caribeños que en su gran mayoría eran jamaiquinos y uno que otro aventurero del valle central. Limón se convirtió en el asentamiento de culturas y tradiciones diferentes al resto del país. Se pretende entonces hacer un estudio de uno de los credos religiosos ampliamente difundido en el Caribe y en lugares del continente americano donde llegaron inmigrantes jamaiquinos, nos referimos a la pocomía.

\footnotetext{
Abstract

The history of the city of Limon is completely different from that of Costa Rica. Its cultural, economic, ethnic and even urban origins (background) are so drastically disparate that it could be said that it is a country within a country. One example that clearly illustrates this difference was the construction of the railroad, a major project that connected the capital with the Caribbean side of the country. The people who worked on the railroad were Italians, Chinese, Central Americans, Coolies from India, Blacks from the Caribbean (mainly Jamaicans), and a few adventurers from the Central Valley. Thus, Limon became a hub of unique culture and traditions, distinct from the rest of the country. A study will be made of Pocomia, one of the religious creeds that was widely diffused in the Caribbean and in other parts of the American Continent where Jamaican immigrants arrived.
} 


\section{Introducción}

Los pueblos africanos al igual que muchos otros tenían sus propias creencias y cosmogonía. Sus raíces culturales han sido tan poderosas y han estado tan arraigadas en su "vida espiritual" que lograron no solo conservarlas sino que, al llegar al nuevo mundo como esclavos, se desarrollaron de tal forma que surgieron nuevas manifestaciones religiosas, todas con una profunda raíz africana. Con el inicio de la trata de esclavos negros africanos en el siglo XVI, millones son extraídos de sus pueblos y llevados a tierras desconocidas para ellos. Lejos de su patria y de su familia, encontraron una forma de mantenerse unidos sin importar su origen tribal. Nos referimos a sus creencias, tradiciones y religiones las cuales les ayudó a mantener una unión espiritual con su continente.

El culto, que forma parte de cualquier credo religioso y se manifiesta de diferentes formas, también fue practicado por los pueblos africanos a sus antepasados y a sus dioses ${ }^{1}$. Este culto fundamentaba sus creencias, su moral y su mundo espiritual. Los esclavos africanos traídos a América no eran unos "salvajes" ya que poseían una cultura y creencias propias que no fueron aceptadas por los europeos que por su parte los consideraban "salvajes". Con lo que respecta a las colonias inglesas del Nuevo Mundo, predominaba la influencia de los pueblos akan de la costa occidental actual Ghana, que hablaban en Ashanti, fanti y otros dialectos del twi. Una característica de estos pueblos era su fuerza física, resistencia y su rebeldía por lo cual eran temidos por los europeos. Por esa razón, una práctica del esclavista era mesclar a los esclavos para evitar una sublevación.

Al llegar al Nuevo Mundo y a pesar de la intención del esclavista de mantenerlos separados de acuerdo a su tribu, hubo dos aspectos que los mantuvo unidos, el primero fue su mundo espiritual y el segundo su condición de esclavo. Con lo que respecta a la religión, los ingleses eran protestantes y por tanto no creían que los negros esclavos tenían alma y por eso el bautizo no era necesario ya que no había nada que salvar. Se puede afirmar que el acceso tardío a las religiones cristianas permitió la práctica de credos religiosos africanos de toda índole. La mayoría de los pueblos del África occidental creían en el obeah o brujo, el cual podía llevar a cabo algún hechizo por medio del uso de plantas, algún conjuro o por medios psíquicos. El obeahman era considerado como un brujo practicante de la magia negra. Otra creencia era el culto al myalismo que era considerado como antibrujería y se basaba en ritos de posesión de espíritus ancestrales. El líder del myalismo era considerado como un guía espiritual y practicante de la magia blanca. Por último tenemos la práctica de la religión conocida como kumina.

La religión kumina es practicada entre el llamado pueblo bongo (descendientes de los esclavos bantú quienes permanecieron en las plantaciones, cuyos ancestros

\footnotetext{
${ }^{1}$ En el caso propio de los Akan, pueblo de la costa occidental africana, creían en un ser supremo como creador y en un Dios.
} 
vinieron del Congo y Angola)... Ellos se establecieron como devotos de una deidad suprema centroafricana (Nzambi) con arraigadas costumbres, que incluía kumina (tambores, danza y la posesión ancestral de espíritus), sacrificio de animales, intuición y saneamiento de hierbas. Las prácticas kumina se basan en la familia, por lo que las casas de los practicantes sirven de puntos ceremoniales. El canto de kumina sigue el llamado africano y los patrones de respuestas: una línea o verso es cantado por el cantante principal y luego el resto de los participantes responden repitiéndolo. El principal ritual kumina es la danza "memorial" que una determinada familia la hará en honor a sus ancestros. Los tambores y el canto en kikongo (una lengua antigua centroafricana) sirve como una forma para llamar el espíritu de un ancestro que se cree que "posee" el cuerpo de un adorador quien luego empieza a bailar bajo trance que puede durar desde unos minutos a varias horas. El ritual se termina con un sacrificio de un animal (cabra o pollo), cuya sangre es usado junto con ron para alimentar a los ancestros. Estas prácticas religiosas son similares al vudú en Haití y shango en Trinidad y Tobago ${ }^{2}$.

Estas creencias y prácticas religiosas no motivo ningún desvelo por parte del europeo esclavista, sin embargo, poco a poco los esclavos fueron uniéndose en espíritu y bajo la guía de un líder espiritual y fue entonces cuando el europeo opresor se empezó a preocupar y con justa razón. Se considera que los levantamientos de esclavos estuvieron dirigidos por obeahman y myalistas que se unieron en su lucha contra el esclavista. Una de las rebeliones más memorables en la historia de Jamaica fue la de los maroons o cimarrones $^{3}$. "Al no poder dominar a los maroons, los ingleses se vieron obligados a concertar con ellos dos arreglos pacíficos (1738 y 1739). A cambio de la libertad reconocida oficialmente por los colonizadores y de la autonomía...". Como bien lo dice Nitoburg ${ }^{4}$, la mayoría de los cultos en Jamaica se basaban en la creencia de los maroons que a nuestro parecer se encontraba íntimamente ligado al obeah y al myalismo. No menos importante es el movimiento iniciado por el llamado "Moisés Negro" Marcus Garvey de principios de siglo XX, el cual, según Francisco J. Concepción Márquez en su artículo titulado "Myalismo y Obeah: Sincretismo y Poder", el movimiento de Garvey "viene con la fuerza del myalismo en su interior" ¿ ¿Pudo esa fuerza del myalismo haber llegado a otros países por medio de la diáspora africana? De acuerdo a situaciones propias de la historia de

\footnotetext{
${ }^{2}$ Clifton L. Holland ed., Enciclopedia de grupos religiosos en América Latina y el Caribe: Religión en Jamaica, trad. Carmen Luna Hernández (San José: PROLADES, 2011 [citado el 26 de marzo del 2016]): disponible en http://www.prolades.com/encyclopedia/countries/spanish/rel jamaica09spn.pdf

${ }^{3}$ Esclavos negros fugitivos.

${ }^{4}$ Eduard Nitoburg, Los africanos en el nuevo mundo. El elemento negroide en la formación de las nacionalidades en América, trad. Pavel Boyko (Moscú: Progreso, 1991), 284.

${ }^{5}$ Concepción Márquez, "Myalismo y Obeah: Sincretismo y Poder", Kálathos: Revista Transdisciplinaria Metro-Inter 6, no. 2 (2012-2013 [citado el 26 de marzo del 2016]): disponible en http://kalathos.metro.inter.edu/kalathos mag/publications/archivo5 vol6 no2.pdf
} 
Costa Rica y en caso particular de la historia de los movimientos sociales en la ciudad de Limón de principios de siglo XX, si fue posible y eso será demostrado más adelante.

Con lo que respecta a la pocomía, su origen es el resultado de un avivamiento evangélico que se dio en Jamaica a finales del siglo XIX. Ese avivamiento se dividió en dos grupos, el de zión y el de la pocomía. Sus ritos son muy similares y por eso es difícil diferenciarlos. Sin embargo, de acuerdo a sus prácticas podemos determinar algunos aspectos en común como lo fueron la lectura de la Biblia, el canto, la predicación, el baile rítmico pero sin el uso del tambor y la invocación de los espíritus.

En Bocas del Toro y propiamente en la "zona del canal", las actividades de los pocomías recibieron la "bendición” de la compañía bananera que gobernaba en esa región del canal. Por esa razón no se ocultaban e incluso llegaron a tener sus propios templos. Sin embargo, la pocomía en Limón siempre fue rechazada por las autoridades locales y nacionales. Se reunían en lugares alejados de la ciudad y sus ritos se iniciaban en horas de la noche. La pocomía se convirtió en una organización secreta cuyos miembros eran inmigrantes jamaiquinos que juraban fidelidad a sus líderes y un rotundo secreto a sus rituales.

La pocomía fue una organización que surgió en medio de las vicisitudes de la población negra inmigrante caribeña. Muchas personas llegaron a confundir las logias masónicas con la pocomía. Incluso, algunos hablaban de "logias pocomías". Con lo que respecta a las logias, a principios del siglo XX se podían leer publicaciones en periódicos locales donde mencionaban aspectos relacionados con sus actividades sociales y acuerdos tomados por sus miembros. Pertenecer a una logia llegó a dar un status diferente entre la población limonense. Los grandes maestros de las logias eran invitados a actividades sociales y celebraciones patrias. Sin embargo, entre las décadas de 1980 y 1990, se empezó a confundir las logias con la pocomía.

Uno de los aspectos que provocó la confusión es que en ambos sus integrantes eran negros inmigrantes caribeños. La celebración de sus actividades eran en horario nocturno y el secretismo también se conjugó en la confusión de las personas. A finales del siglo XX fue la época de extinción de las logias y muy posiblemente de la pocomía. El crecimiento de la ciudad y el surgimiento de una gran cantidad de credos evangélicos posiblemente jugaron un papel importante en la desaparición de la pocomía en Limón. Otro aspecto es que sus líderes habían muerto y muy posiblemente emigrado.

\section{Creencias y tradiciones de los inmigrantes caribeños de Limón.}

Los inmigrantes caribeños llegaron a Limón con muchos sueños y esperanzas. Venían contratados por una compañía extranjera que era dirigida por Minor Keith. Trabajarían para ayudar a sus familias que esperaban su pronto regreso a su patria. Trajeron consigo no solo su fuerza de trabajo sino que también todo un mundo religioso y espiritual 
presente en Jamaica de finales de siglo XIX la cual se encontraba envuelta en un sincretismo religioso. La gran mayoría de los inmigrantes caribeños eran cristianos protestantes influenciados por Inglaterra y los Estados Unidos. En el año 1888 se estableció en Limón la primera iglesia bautista convirtiendo a la ciudad en el principal centro religioso bautista de Centroamérica. Este credo era profesado por la mayoría de los inmigrantes caribeños. Posteriormente surgieron los metodistas y anglicanos aunque no todos los inmigrantes eran protestantes. Un importante grupo profesaba la religión católica y en su mayoría eran de la isla de Santa Lucía ${ }^{6}$.

Desde el punto de vista político, el edificio del Black Star Line construido en 1922, representaba la historia de la voz de los negros y de uno de los grandes líderes de principios de siglo XX, Marcus Garvey. Aunque su ideal y deseo de regresar a África no se concretó, el edificio se convirtió en el centro cultural de los negros de Limón. Poco a poco los inmigrantes aprenden a congregarse en organizaciones como la iglesia, la UNIA (Asociación Universal para el Mejoramiento del Negro) creada por Garvey y la logia que los amparó y protegió. De acuerdo con Ricardo Martínez Esquivel "las logias constituyen un espacio idóneo para el libre pensamiento y expresión, por lo que entre sus miembros es común encontrar personas de distintas procedencias, ocupaciones e incluso religiones"7.

Es así como, el inmigrante caribeño llegado a Limón presentaba una cosmovisión del mundo muy diferente a la realidad costarricense y eso marcaría su futuro social, cultural y religioso hasta nuestros días. A partir de su llegada comprendió su situación de extranjero en un país que hablaba un idioma diferente al suyo, un país cafetalero cuando ellos tomaban té, un país católico cuando ellos eran protestantes, un país que había sido colonizado por una ex potencia cuando ellos aún pertenecían a una potencia. Se encontraban además sin sus familias, lejos de su patria y sometidos a arduas horas de trabajo bajo condiciones insalubres y con un clima tropical propio de una "selva "que había que abrir y conquistar. Todas esas circunstancias también propiciaron la unión que a su vez posibilito el fortalecimiento de su espiritualidad, su folklore, sus creencias y su identidad jamaiquina con raíces africanas. Es así como se justifica el surgimiento en Limón de tan diferentes cultos religiosos y asociaciones que los mantenía unidos. Pero, además de las religiones protestantes, las logias, la UNIA y otras organizaciones de bien social, surgió el culto de la llamada pocomía. Muy probablemente entre los trabajadores jamaiquinos llegados a Limón a principios del siglo XX llegó uno que otro practicante de la pocomía, culto prohibido en Jamaica y que era muy bien conocido por todos sus coterráneos.

\footnotetext{
${ }^{6}$ Anita Calimore Forbes, "Raíces de la comunidad negra católica de Puerto Limón" (Tesis de Licenciada en Teología, Universidad Nacional de Costa Rica, 1993).

7 Ricardo Martínez Esquivel, "Sociabilidades modernas: sociedades fraternales secretas en el Caribe costarricense a finales del siglo XIX", MEMORIAS. Revista digital de Historia y Arqueología desde el Caribe colombiano 7, no. 12. (2010 [citado el 14 de agosto de 2015]): disponible en http://rcientificas.uninorte.edu.co/index.php/memorias/article/viewArticle/516/5109
} 


\section{EI movimiento nativo bautista de Jamaica}

Este movimiento empezó con la llegada del predicador bautista negro (George Liele) de Georgia en 1783, "quien acompañó a los leales británicos quienes se negaban a vivir en la recién independiente Estados Unidos de América". Cabe mencionar que, desde el punto de vista del cristianismo, un avivamiento es un despertar religioso en un determinado lugar, en este caso en los Estados Unidos. "Para los cristianos, los avivamientos son procesos de conversión espiritual motivados por Dios, y en ocasiones suelen ser vistos como procesos restauracionistas.

Los avivamientos reconocidos en Estados Unidos, se dan entre 1730 y 1740 el primero, y el llamado Segundo Gran Despertar, entre 1790 y 1840. Sobre los sermones la misma fuente indica que la gente se volvió más apasionada y emocionalmente involucrada con su religión, en lugar de escuchar pasivamente al discurso intelectual de manera indiferente ${ }^{9}$. Este aspecto es importante ya que menciona una característica de los cultos africanos en relación a "su participación activa en sus rituales". La participación activa de los cultos africanos reflejada por medio de las posesiones era algo que empezaron a practicar los evangélicos como los bautistas.

El avivamiento evangélico llegó a Jamaica antes de la abolición de la esclavitud en 1834. El movimiento bautista nativo incorporó las prácticas y culto del myalismo y las creencias y prácticas del cristianismo evangélico. Sin embargo, en el movimiento nativo bautista predominaba la práctica myalista sobre las creencias religiosas, así que para esa época no podemos hablar aún del surgimiento de un sincretismo religioso. No fue sino hasta 1860 cuando se origina en Jamaica un avivamiento que dio origen a un verdadero sincretismo religioso entre el myalismo y los bautistas nativos. Este avivamiento fue llamado el "avivamiento de Sion" que se concretó con el surgimiento de la pukumina o pocomía. Se origina así un culto religioso con raíces africanas y prácticas cristianas evangélicas. ¿Por qué proliferó este sincretismo? La práctica del myalismo tenía varios aspectos en común con el movimiento bautista nativo: Ambos practicaban la posesión espiritual, el hablar en lenguas y la cura de los feligreses y por eso su popularidad.

El sincretismo religiosos surgido en Jamaica fue diferente a otros sincretismos del Caribe como por ejemplo, el de la santería en Cuba. A diferencia de lo sucedido en Jamaica, en Cuba no hubo ningún avivamiento y más bien el surgimiento de la santería fue el resultado de la llamada "aculturación antagonista", “...mediante la cual la cultura dominada adopta los aspectos externos (significantes) de la cultura dominante, pero no así

\footnotetext{
${ }_{9}^{8}$ Holland ed., Enciclopedia de grupos religiosos, 46.

${ }^{9}$ Sydney E. Armstrong, A Religious History of the American People (New Haven y Londres: Yale University Press, 1972), 263.
} 
los fines o significados de ésta. De esto se desprende, por ejemplo, el extendido uso de los santos católicos dentro de un contexto mítico y ritual que no les es propio ${ }^{10}$.

Como vemos, este último aspecto no fue una práctica dentro del avivamiento de Sion ya que el sincretismo que iba a surgir no creía en santos.

\section{El obeahman y la Pocomía en Limón}

No se debe pasar por alto el papel del obeahman en un momento de crisis y descontento social por parte de los trabajadores caribeños en el año 1910 donde un obeahman lideró un movimiento huelguístico. Incluso se creó una organización fraternal que terminó funcionando como un sindicato llamada Unión de Obreros y Artesanos o A.L.U. (Siglas en inglés) que de acuerdo con Chomsky fue dirigida por un obeahman ${ }^{11}$. A finales de la década de los años 30 del siglo XX se presentaron una serie de hechos que causaron mayor furor y atención por parte de la población costarricense, pero esta vez no se relacionaría con el obeahman sino con la Pocomía. La Pocomía surge, al igual que el obeahman, bajo unas condiciones muy particulares. A finales de la década de los años 30 del siglo XX, la United Fruit Company. ya había decidido trasladar sus plantaciones de banano al pacífico sur de Costa Rica y, por decreto del presidente Ricardo Jiménez del año 1934, era prohibido utilizar mano de obra negra en esas nuevas plantaciones. Esto significaría el abandono por parte de la UFCo. de los inmigrantes caribeños en la ciudad de Limón. En el año 1938 la UFCo. concluyó el traslado y empezó sus labores en un nuevo territorio. Bajo estas nuevas circunstancias es que aparece el culto de la pocomía en la ciudad de Limón. Pareciera ser que su aparición y práctica resolvió la problemática social de algunos inmigrantes caribeños que encontraron cobijo en un rito que formaba parte de sus raíces africanas y sobre todo de su folclore religioso. Este nuevo culto no respondía a los intereses de la UFCo. ni a los intereses personales de los líderes religiosos que en muchos casos jugaban un doble papel como sucedió durante la huelga de 1910 apoyando a los trabajadores pero convidándolos a regresar a su trabajo. Ahora el nuevo culto formaba parte de su cosmovisión africana y representaba sus intereses espirituales. La pukumina, como se le conoce en Jamaica, o pocomía que proviene de "pequeña locura" en español, tiene raíces africanas y es el resultado de un sincretismo religioso.

Las primeras noticias sobre la Pocomía fueron de la prensa, propiamente del Diario de Costa Rica que en publicación del 20 de setiembre de 1936 titulada "Los sacerdotes del diabólico culto de la cocomía, invaden la zona del Atlántico", menciona con detalle las

\footnotetext{
${ }^{10}$ Gustavo Martín, "Magia, religión y poder Los cultos afroamericanos", Nueva Sociedad 82 (marzo-abril 1986 [citado el 12 de abril del 2015]): disponible en http://nuso.org/media/articles/downloads/1382 1.pdf

${ }^{11}$ Avi Chomsky, "Afro-Jamaican traditions and labor organizing on United Fruit Company plantations in Costa Rica, 1910", Journal of Social History 28, no. 4 (1995): 837-855.
} 
actividades del culto, sin embargo, cometen el error de llamarlo: "Cocomía", demostrando el poco o nulo conocimiento que se tenía del mismo. En el mismo periódico se cita que:

En Cuba estas prácticas han sido expresamente prohibidas por las autoridades, en la inteligencia que la Cocomía es una de las ramas más peligrosa de los cultos demoniacos de antiguas creencias extraviadas, de una especie de magia negra que en épocas de la colonia provocó pavorosos dramas pues se llegó al sacrificio de niños. Las autoridades de la zona han intervenido y detenido en algunas oportunidades a los adeptos de esa secta, pero se les ha liberado por falta de méritos para procesarlos por prácticas que no condena expresamente la ley...Se habla también de un HERMANO TERRIBLE con potestades suficientes para pronunciar sentencias de muerte, que son llevadas a cabo por los adeptos juramentados ${ }^{12}$.

A partir de esa publicación se empieza a identificar el culto con sacrificios humanos, propiamente de niños, iniciándose así la satanización de una actividad que empezaba a practicarse en las cercanías de la ciudad de Limón. En las "Lomas de Miss Arnold" situada a unos dos kilómetros del centro de la ciudad y en dirección a Moín, fueron arrestados unos jamaiquinos acusados de practicar el culto. Los arrestados terminaron siendo acusados de profanadores de tumbas por unos huesos "supuestamente humanos" encontrados en el sitio, no así de practicantes de la Pocomía. Sin embargo, la noticia tomo vuelo y la Pocomía empezaba a ser conocida en todo el país gracias a la publicación de artículos periodísticos en la prensa local y nacional. El culto se identificó como una práctica de los inmigrantes caribeños, propiamente jamaiquinos. El abandono por parte de la UFCo. de esa fuerza laboral fue inminente. Se inicia entonces una lucha con un matiz diferente. No era por reivindicaciones sino más bien por sobrevivir aceptando que volver a su patria estaba muy lejos de ser posible. Ante esta situación algunos emigraron hacia Panamá y otros, como lo dijimos anteriormente, buscaron refugio a sus penalidades en el culto de la Pocomía.

Uno de los supuestos dirigentes de la Pocomía, fue Altiman Krimbel Dabney, el cual se dio a conocer cuando sus actividades aparecieron en medios periodísticos. En La Voz del Atlántico del 7 de noviembre de 1936 el mismo Altiman se defiende alegando toda una serie de situaciones que ha sufrido por parte de las autoridades locales contra su iglesia, la cual desde el año 1932, ha sido desmantelada en dos ocasiones. Altiman se había declarado un líder espiritual y seguidor de Dios. A pesar de eso, terminó siendo deportado no sin antes vociferar una serie de maldiciones contra Costa Rica e incluso contra el presidente León Cortes Castro:

${ }^{12}$ Diario de Costa Rica, "Los sacerdotes del diabólico culto de la cocomía invaden la zona Atlántica", 20 de septiembre de 1936, 5 . 
Bajo este arco iris yo pido a Dios el padre y a todos los santos en el cielo, que se levanten y paren con sus manos extendidas sobre Costa Rica y hagan que el día más luminoso se convierta en la noche más oscura bajo lluvia y viento, truenos y relámpagos, temblores e inundaciones y que salgan los santos del fondo del mar y causen la erupción del volcán ${ }^{13}$.

Coincidencia o no, lo cierto es que meses después de su deportación un gran oleaje destruyó parte del "Balneario Los Baños" recién inaugurado. La repentina muerte del presidente León Cortés también se relacionó con Altiman. Sin Altiman el gobierno consideró un gran triunfo su deportación y consideró que su labor era exitosa contra el diabólico culto. Cabe mencionar que de acuerdo con Harpelle, "la mayoría de los Pocomías habían nacido en Costa Rica y por eso era difícil su deportación" ". Sin embargo, un aspecto que se presentó como una norma en la práctica del culto es que los líderes fundadores eran hombres y extranjeros, propiamente de Jamaica. Si el culto empezó a ser conocido en los años 30 del siglo XX, significa que, no solamente los líderes eran jamaiquinos, sino que muy probablemente sus seguidores también lo eran ya que el proceso de nacionalización de los inmigrantes caribeños se inició en 1949. Pero, a pesar que Harpelle no lo concreta, es posible que se haya referido a los practicantes de la Pocomía posterior a su nacionalización lo cual es una realidad de acuerdo a los relatos de testigos. Lo cierto del asunto es que, bajo estas circunstancias, cualquier manifestación cultural ancestral realizada por los jamaiquinos podría ser considerada como una práctica de la Pocomía.

Otro caso sobre la Pocomía en Limón se presentó en el año 1938. Se relacionó al pastor George Davis de la iglesia "The Pentecostal Baptist Union Church" supuestamente con sede en Oregón, Estados Unidos como un líder de la Pocomía. Davis había llegado a la casa de uno de sus seguidores que había tratado de agredir con un machete a sus vecinos. Al ser detenido y amarrado, el pastor Davis se apersonó a su casa a orar por él y después pidió que se le liberara. Al día siguiente en un acto de locura, el mismo seguidor del pastor Davis asesino a su hermana de 4 años a machetazos. Lo anterior conllevó al arresto de ambos, uno por asesino y el otro por, supuestamente, haber contribuido al hecho. Davis fue liberado al poco tiempo de su arresto sin embargo, no se pudo quitar de encima el ser estigmatizado como líder Pocomía. Harpelle nos indica que Davis había recibido de parte de la UFCo. un terreno y casa donde practicar su culto pero que después de insultar a un funcionario de la compañía se le retiró el derecho de viajar gratis en el $\operatorname{tren}^{15}$. Aquí vemos

\footnotetext{
${ }^{13}$ La Voz del Atlántico, "Defensa del jefe de la secta pocomía Sir Altiman Krimbel Dabney ante la Agencia", 7 de noviembre de 1936,1 .

${ }^{14}$ Ronald N. Harpelle, "Ethnicity, Religion and Repression: The Denial of African Heritage in Costa Rica", Canadian Journal of History 29, no. 1 (1994): 18.

${ }^{15}$ Harpelle, "Ethnicity, Religion and Repression", 4.
} 
el papel de la UFCo. en relación al credo de los inmigrantes caribeños y por qué a veces los pastores jugaba el llamado "doble juego" cuando se presentaba algún movimiento huelguístico. En 1938 la iglesia de Davis fue requisada por la policía y nuevamente es arrestado y acusado de continuar con la práctica de la Pocomía. Al igual que la primera vez, fue liberado al poco tiempo de su arresto.

Otro suceso que vinculo a Davis como líder Pocomía fue el relacionado con el supuesto secuestro de un niño por parte de una negra jamaiquina. El niño que había logrado escapar de sus raptores, fue obligado por la mujer a extraer huesos humanos enterrados. Posteriormente, su padre se presentó ante las autoridades a denunciar el hecho. Los agentes de policía acudieron con el niño a los lugares donde había sido conducido por la secuestradora. En una casa encontraron entre muchos objetos un rótulo donde se encontraba escrito G. Davis Capitán ${ }^{16}$. Por su parte el señor Davis se defendió de tales acusaciones en una publicación del periódico La Voz del Atlántico del 26 de febrero de 1938, negando ser practicante de la Pocomía o tener algún vínculo con Altiman. A Davis se le prohibió ejercer la práctica del culto y si no se le expulsó fue porque no se pudo comprobar que era un peligro para el país o incluso el presidente. Por lo menos no vociferó contra su persona ni lanzó ninguna maldición en particular como lo hizo Altiman antes de ser expulsado de Costa Rica.

\section{La Pocomía en la literatura costarricense}

Aunque parezca inverosímil, la primera narración sobre la Pocomía fue descrita por Carlos Luis Fallas en su novela Mamita Yunai. El gran líder del partido comunista fue desterrado en 1933 por los tribunales de San José a Limón por un año. Toda su vivencia y futura participación en la huelga bananera de 1934 fue descrita por Fallas en su libro. En relación a la Pocomía y la descripción en su libro, Fallas le llamó el "baile del ron".

Cantaban en inglés, formados en rueda, una canción salvaje y monótona y se acompañaban dando palmadas con las manos y pateando con ritmo en el suelo. Giraba la botella de mano en mano, y cada uno que la iba cogiendo se la empinaba doblándose hacia atrás. Chispeaban los ojos, burbujeaba el ron colorado en la botella y se aceleraba el ritmo del baile. Y caía una botella vacía haciéndose pedazos en la línea y otra llena iniciaba la vuelta. Al poco rato ya estaban aullando con los ojos en blanco y la rueda deshecha.

Uno zapateaba vertiginosamente haciendo movimientos inverosímiles con los pies. Otro se descoyuntaba la cintura en una danza obscena y lujurioso. El de más allá, con las manos en la barriga, y en un solo lugar, le imprimía al cuerpo, de arriba abajo, un movimiento ondulante, de serpiente, mientras tiraba la cabeza

\footnotetext{
${ }^{16}$ El subrayado es del autor.
} 
adelante y la volvía a recoger estirando la trompa. Un negrazo alto y robusto, desnudo de ombligo para arriba, daba vuelta al cuarto a grandes zancadas, con los ojos brillantes y bramando como un toro que celara a la vacada.

Y todos aullaban, se estremecía el campamento como si millones de demonios estuvieran metidos allí.

Terminaban la fiesta tendidos como troncos. Era un montón de carne sudorosa que roncaba con estrépito ${ }^{17}$.

Según Maureen Raphael de la Universidad de las Indias Occidentales ${ }^{18}$, la descripción de Fallas coincide en gran medida con la práctica de la Pocomía en su país. Con lo que respecta al estudio sobre las características de la Pocomía, lo único que se excluiría del relato es el ron ya que el culto como tal no permite el consumo de licor. Sin embargo, si se pasa por alto el consumo del ron, todo lo demás coincide con la práctica del culto.

Mientras tanto, en Panamá ya se había fundado un credo religioso con prácticas similares a la Pocomía de Limón como se verá a continuación.

\section{El Bedwardismo en Panamá y su relación con la Pocomía}

En 1890 surgió en Jamaica el Berwardismo que era un movimiento evangélico liderado por el profeta Alexander Bedward y que en 1891 estableció la Iglesia Libre Bautista Nativa de Jamaica con profundas raíces africanas ${ }^{19}$. De acuerdo con Roy Simón Bryce-Laporte, su líder Alexander Bedward, trabajó en Colón y en 1886 tuvo una visión decidiendo volver a Jamaica y fundar una iglesia para salvar su alma y la de sus $\operatorname{compatriotas}^{20}$. Aunque Broyce no indica cuándo o cómo empezó a practicarse este nuevo culto en Panamá, se considera que inicia gracias a los inmigrantes jamaiquinos. Lo que si afirma Broyce es que el culto era llamado "Jumpy-Jumpy",21.

Broyce no llama al culto del Bedwardismo pukumina o pocomía, sin embargo, asegura que,

\footnotetext{
${ }^{17}$ Carlos Fallas, Mamita Yunai (San José: Editorial Costa Rica, 2008), 168-169.

${ }^{18} \mathrm{O}$ Universidad de las Antillas (en inglés, University of the West Indies) es una institución educativa financiada por quince gobiernos del Caribe: Anguila, Antigua y Barbuda, Bahamas, Barbados, Belice, las Islas Vírgenes Británicas, las Islas Caimán, Dominica, Granada, Jamaica, Montserrat, San Cristóbal y Nieves, Santa Lucía, San Vicente y las Granadinas y Trinidad y Tobago.

${ }^{19}$ Holland ed., Enciclopedia de grupos religiosos, 46.

${ }^{20}$ Bryce-Laporte, Roy Simon, "Religión Folklórica y Negros Antillanos en la Zona del Canal de Panamá", Revista Nacional de Cultura 5 (1976): 524.

${ }^{21}$ Bryce-Laporte, "Religión Folklórica y Negros Antillanos", 523.
} 
Las prácticas y la parafernalia del culto Benjinite ${ }^{22}$ en el istmo tiene un gran parecido a varios otros cultos jamaicanos de orientación africana, algunos tales como cúmina, etú, convince, mialismo, pocomía, tiene sus orígenes desde los días de la esclavitud en dicha isla y otra son parte de las erupciones extensas de reavivamiento que comenzaron a surgir en Jamaica alrededor de $1861^{23}$.

Así que en Panamá y propiamente entre los emigrantes caribeños que vivían cerca de la zona del Canal surgió un sincretismo religioso evangélico.

En relación al culto practicado en Panamá, se entrevista a Miss Catalina Brown Brown de 100 años de edad y residente en Suretka, Talamanca. Ella había pertenecido a una logia en Almirante lugar donde vivió y trabajo. Cuando se le pregunta si conocía de la existencia del culto de la Pocomía en Panamá, respondió lo siguiente:

La misa era en el patio, al aire libre, en Bocas y en Almirante. Aunque ya casi no se ven. Los Pocomías hacían un fuego en el patio. Pero yo no le puedo decir si los Pocomías mataron a alguien aquí en Limón. En una casa donde nosotros vivíamos en Almirante había un patio grande y una vecina nos pedía permiso para hacer sus cosas de la Pocomía ahí, pero nosotros nunca vimos ningún sacrificio. Bailaban alrededor del fuego, rezaban y cantaban góspel, entraban en trance y hablaban en lenguas. Ellos no tomaban licor. La madre superiora usaba un turbante rojo y le decían "Madda". Los demás, dependen del grado que tenían usaban un turbante amarillo o blanco y todos usaban ropa blanca pero solo en la misa. Si era un velorio el color del turbante era púrpura. En el día de "Acción de Gracias" la gente llevaba comida al lugar y se repartía entre los que llegaban. Ahí no había nada malo ${ }^{24}$.

Ese testimonio deja de manifiesto algunas particularidades del culto siendo uno de los más destacados el que se reunían al "aire libre" y no es un templo.

En Panamá, propiamente en Changuinola, se entrevista al teniente J. Binns sobre la existencia de la Pocomía. Responde que no existía en Panamá, sin embargo, cuando se le menciona que era lo que practicaban los inmigrantes caribeños de acuerdo al relato de la señora Brown, la respuesta fue otra: - "Ah, eso se llama jumpy- jumpy, son evangélicos” -.

Al preguntarle sobre la posible vinculación del rapto de niños o ritos satánicos por parte de sus miembros, respondió que nunca había sabido o escuchado cosas como esas. Indicó que en el "barrio francés" o "Patua Town" existe un templo ${ }^{25}$. Posteriormente se descubre que existen cuatro iglesias practicantes del culto jumpy-jumpy. Sus nombres son: El templo de la Iglesia San Judas Tadeo Bautista Internacional \#2, la Iglesia Monte Puron

\footnotetext{
${ }^{22}$ Así también eran llamados a los seguidores del Bedwardismo.

${ }^{23}$ Bryce-Laporte, "Religión Folklórica y Negros Antillanos", 525.

${ }^{24}$ Se respeta el lenguaje coloquial del entrevistado que no habla bien el español. C. Brown, comunicación personal, 5 de marzo del 2013.

${ }^{25}$ J. Binns, comunicación personal, 1 de septiembre del 2015.
} 
Bautista Internacional \#3, la Iglesia de la Roca en la isla de Bocas del Toro y otra Iglesia de la Roca que se encuentra entre Changuinola y Almirante. Se logra contactar y entrevistar a miembros de las dos primeras Iglesias llamadas por ellos "Iglesias Espirituales". El nombre de la líder de la Iglesia Monte Puron es la señora Yolanda ${ }^{26}$ que es la fundadora y obispa del templo que construyó al frente de su propiedad. La señora Yolanda aseguró que ellos no practican la Pocomía y que son una iglesia evangélica espiritual fundada en Jamaica en 1910. El nombre de su iglesia que se encuentra debidamente registrada ante las autoridades respectivas tiene por líder a una mujer jamaiquina que vive en Colón. Sobre sus prácticas la señora Yolanda brindó la siguiente información:

Antes de construir el templo las reuniones se llevaban a cabo en el patio de la casa. El uso de los turbantes que se consideran sagrados es solo para misas especiales. Practican el bautizo pero no a los recién nacidos ya que la persona es la que va a determinar el momento preciso de su bautizo de acuerdo a la madurez que posea. El día del bautizo la celebración empieza en la madruga, los feligreses se reúnen en el templo y caminan hacia un río que se encuentra cerca donde realizan el bautizo, hasta ese momento puede usar su turbante. Las velas son muy importante en sus cultos ya que se relaciona con la luz de Dios. En días festivos colocan una mesa iluminada por una gran cantidad de candelas y con platos de comida. Bailan alrededor en dirección contraria a las manecillas del reloj. Esas actividades tienen hora de inicio pero no de conclusión. El templo fue inaugurado a principios de enero del 2015 con la presencia de la líder de Panamá. Usan plantas para la decoración del templo. La señora Yolanda dijo ser diácono y tener el poder de dirigir una misa en ausencia de la Madda. En el centro del templo se encuentra una cruz de madera y en la base una planta llamada por ellos "el árbol de la vida". La planta y su uso son para fines decorativos y no curativos. Se reza y se dan vueltas alrededor de una cruz de madera que mide aproximadamente un metro y medio de alto.

Como anécdota, doña Yolanda comentó que hace unos años atrás, ella y otros hermanos, participaron en una actividad evangélica que reunió a muchas iglesias de diferentes religiones a un convivió en la ciudad de Limón. Lo anterior coincide con el relato de la señorita Andrea Víquez residente en Limón la cual relató que en una actividad de alabanza participaron muchas iglesias de todos lados, hasta de Panamá: "Lo que me llamó la atención de esa reunión fue que ellos, los de Panamá, llevaban un turbante blanco en sus cabezas y todas eran mujeres. Brincaban y daban vueltas en el suelo mientras oraban y cantaban" ${ }^{27}$.

Otra situación relacionada con la práctica del culto en Panamá se presentó durante el "Primer Encuentro de Historiadores e Investigadores Afrodescendientes" donde el autor

${ }^{26}$ Y. Callender, comunicación personal, 26 de marzo del 2014.

${ }^{27}$ A. V. Marín, comunicación personal, 12 de mayo del 2012. 
participó con la ponencia "La Pocomía en Limón". Uno de los asistentes, la señora Anyl Berrie confesó que por fin había entendido por qué su bisabuela vestía de blanco y con un turbante en la cabeza cada vez que iba a misa. "Crecí llamando a mi abuela "Madda" pero siempre creí que eso era por cariño y nunca, hasta ahora, la había relacionado con la Pocomía y que ella era una líder de una de esas iglesias" ${ }^{28}$.

\section{¿Iglesias Espirituales? ¿Madda o Capitán? ¿Pocomía, Sion o Benjinite?}

Es imposible no reconocer la existencia de un vínculo entre la práctica de la pocomía en Limón y su contraparte en Panamá. En el caso de Panamá, se determina que los actuales líderes de las "Iglesias Espirituales" en la provincia de Bocas del Toro son mujeres lo que podría considerarse como una referencia de género en relación a sus fundadores. Sin embargo esa no fue la realidad ya que como lo indica La Porte, fue Alexander Bedward el que originó las iglesias Benjinite que actualmente son llamadas "Iglesias Espirituales". Por otro lado, la señora Diana, nos aseguró que el fundador de la iglesia San Judas Tadeo fue un hombre llamado el "Patriarca" u "Obispo viajero" de nombre Burtel Pussy y conocido como "Buchy" (q.e.p.d.) ${ }^{29}$. Después de su muerte, las mujeres tomaron el control y liderazgo de las iglesias espirituales.

Las señoras Diana y Yolanda comentaron en entrevistas por separado que las iglesias espirituales también son conocidas como Pocomías aunque las autoridades policiales y la población de la provincia de Bocas del Toro los llaman jumpy-jumpy. El término jumpy-jumpy es más coloquial y consecuente con la forma como se práctica del culto. A pesar de la aceptación por algunos lugareños, los vecinos de los templos hasta el día de hoy siguen burlándose por la forma de vestir y de llevar a cabo sus rituales. Otro aspecto que se le critica a estas iglesias es que han sido relacionados con prácticas de brujería u obeah, en este caso, obeahwoman. Al respecto la señora Diana comenta lo siguiente:

...muchas veces la gente es mala. Dios nos da ciertos dones y nosotros tenemos que desarrollarlos Ellos mismos te preguntan.- oye ayer soñé con un niño gordo qué puedo hacer-, o - el niño está enfermo que hago-, entonces une les dice báñenlo con esto y lo otro para ayudar al niño, y cuando se cura andan diciendo que una es bruja. Pero eso no es brujería. A cada quien Dios le dio un don.

Agregó que el uso de determinada planta es indicado por el espíritu de Dios y es a través de ella o de otro hermano de la Iglesia que se ayuda al necesitado. Las plantas se

\footnotetext{
${ }^{28}$ A. Berrie, comunicación personal, 12 de julio del 2015.

${ }^{29}$ D. Steward, comunicación personal, 12 de noviembre del 2013.
} 
utilizan para baños e infusiones pero de igual manera es acompañado por la oración y solicitud de la intercepción de Dios.

En cuanto a la práctica del culto en Panamá y en Limón y tomado en consideración el aporte de Bryce-Laporte ${ }^{30}$, el avivamiento de Sion se dividió en dos grupos: Sion y Pukumina o Pocomía. El Avivamiento de Sion tenía práctica más cercana al cristianismo mientras que la Pocomía es más africana en sus actividades. Sin embargo, Bryce-Laporte no especifica qué tan africana es la Pocomía como lo afirma. Lo que sí se puede especificar es que a Limón llegó la Pocomía y a Panamá los seguidores de Alexander Bedward.

Se puede afirmar entonces que en la ciudad de Limón, todos los líderes de la Pocomía, de acuerdo a las informaciones periodísticas eran hombres y eran llamados "capitán" o "pastores". Recordemos a Altiman y el caso del secuestro del niño donde en la casa donde se le mantuvo raptado se encontró un rótulo con el escrito "Capitán Davis".

En el caso de Panamá, son llamados jumpy-jumpy y pocomías aunque ellos se denominan "Iglesias Espirituales". Actualmente todos sus líderes son mujeres y se les llama "Madda". Dentro de sus prácticas se menciona la posesión espiritual y el mensaje del poseído. Todo esto es vinculante con el myalismo, sobre todo lo de la posesión espiritual. Además, a pesar de las múltiples críticas y burlas hacia sus adeptos, las iglesias existen hasta el día de hoy.

El autor pudo asistir como invitado a la Iglesia San Judas Tadeo de Bocas del Toro que se ubica en "Patua Town". La visita era sumamente importante tomando en consideración que la práctica de la pocomía en Limón ha desaparecido por completo y tan solo quedan recuerdos en la memoria colectiva de la población. Por tanto, se determina que la única posibilidad de adentrarse en la práctica de sus rituales es visitar alguna de la "Iglesias Espirituales de Bocas del Toro. Por eso la importancia de visitar la iglesia San Judas Tadeo Bautista Internacional \#2. El nombre se debe a que, años atrás, una de las líderes pidió la intersección de San Judas Tadeo el cual, según doña Diana líder de la iglesia, fue curada y en agradecimiento bautiza el templo con su nombre.

\section{Vivencias en la Iglesia San Judas Tadeo de Bocas del Toro, Panamá}

El culto inició a las cinco de la tarde, aunque los preparativos empezaron en la mañana del mismo día. Nos guío al templo una de los integrantes que salió a nuestro encuentro, ningún temor a ser vista, con su traje. En la entrada del templo y sobre el piso había un frasco de vidrio con una planta llamada Caña India y conocida como "Flor de Lindero"31 junto con un par de ramas de Ginger. Al frente del frasco se encontraba una vela. Mi guía me tomó de la mano y me dio una vuelta completa alrededor de la planta.

\footnotetext{
${ }^{30}$ Bryce-Laporte, "Religión Folklórica y Negros Antillanos”, 525.

${ }^{31}$ Es usada para delinear el límite territorial de fincas, marcan el lindero y de ahí su nombre popular.
} 
Después me condujo a una silla para que me sentara. La guía explicó que se debía dar una vuelta a la planta e ir hacia el altar hacer un rezo y luego presentarse a los feligreses. Doña Diana dirigía el culto con la ayuda de sus cuatro asistentes.

Imagen 1

Caña India o Flor del lindero

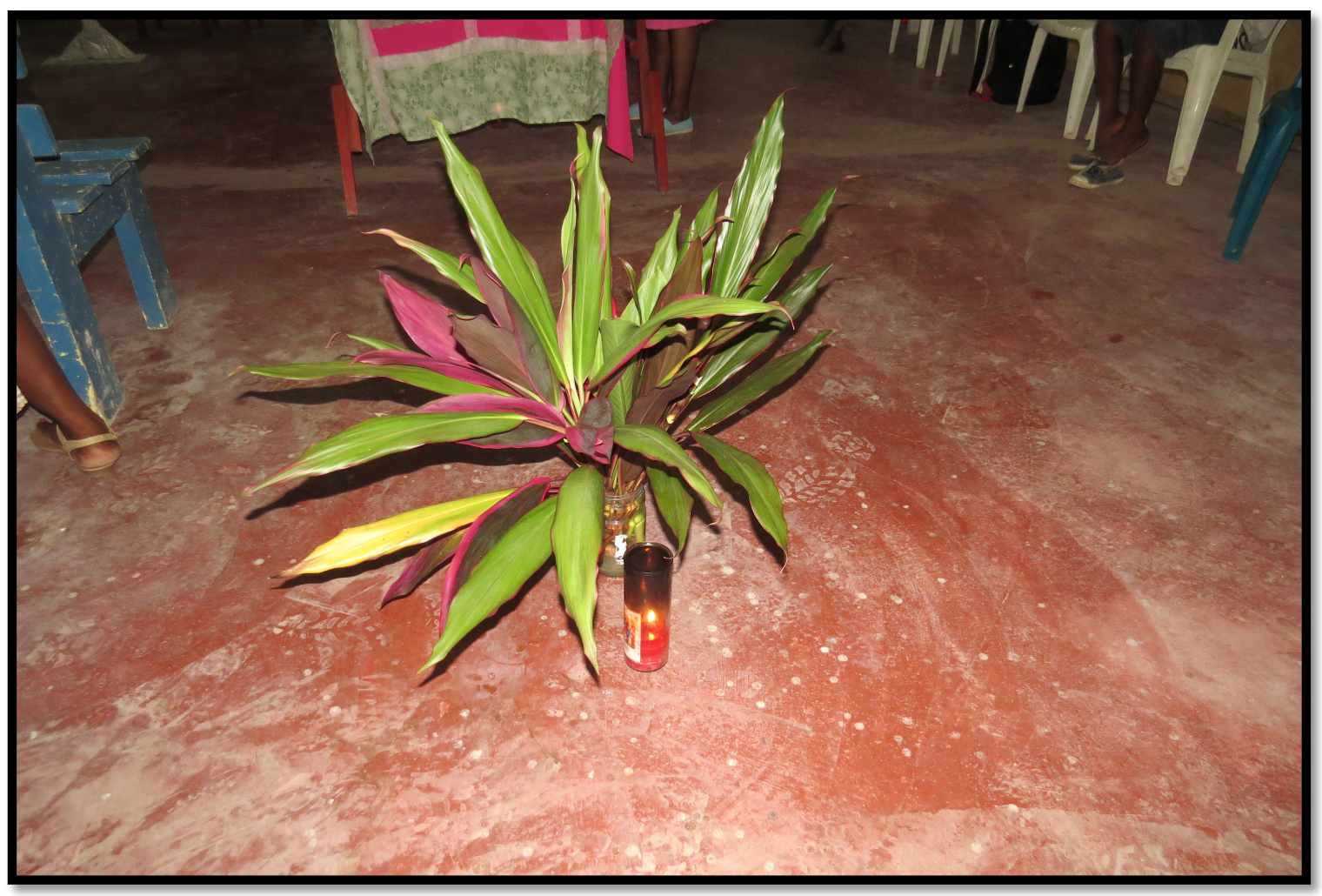

Fuente: Iglesia San Judas Tadeo.

Utilizaba la Biblia y un libro de cánticos religiosos o góspel. Toda la actividad se realizaba en inglés. 
Imagen 2

Mesa ceremonial (nótese el número de ofrendas)

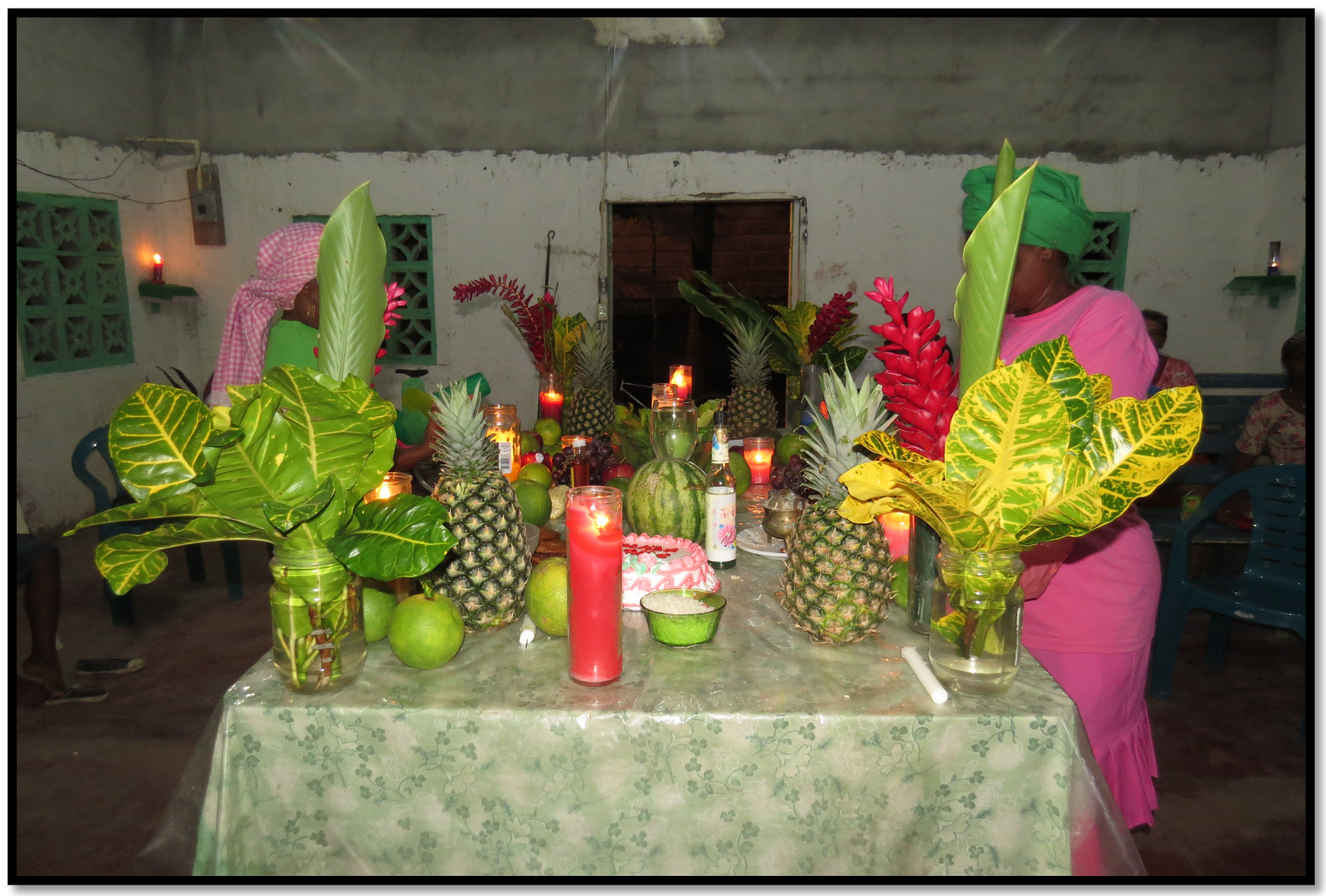

Fuente: Iglesia San Judas Tadeo.

En el centro del templo había una mesa rectangular y sobre ella una gran cantidad de velas, panecillos, frutas y un gran frasco lleno de leche. En las esquinas de la mesa unos frascos de vidrio con Ginger y Crotos. Las asistentes secundaban a la líder que llevaba que llevaba el orden de los cantos. El ritmo era lento pero se cantaba con mucho vigor. Había otros invitados que acompañaban a las cantantes que estaban sentados a un lado de la puerta de entrada que era la única puerta de acceso al lugar. En total había doce personas, diez adultos y dos niños familiares de los presentes. El autor era el único hombre. Los invitados vestían ropa particular y solo las cinco mujeres que dirigían el culto estaban uniformadas y con un turbante en la cabeza. Toda su ropa era de color púrpura y otras de color verde. Ese día celebraban el novenario a San Judas Tadeo. Los cantos eran la tónica de la actividad. Mientras cantaban permanecieron frente a la mesa. Se podría decir que ese era el altar de las ofrendas. Después comenzaron una de ellas empezó a moverse en sentido contrario a las manecillas del reloj e iba prendiendo una vela de la mesa, cuando volvía a su lugar otra hacía los mismo y así hasta encender todas las velas de la mesa. Se movían con mucho ritmo y sin dejar de cantar. Una de las asistentes tomó una botellita de "Agua Florida" y arrojó un poco en cada esquina del templo, luego dio un poco a todas las 
personas que para recibirla debían abrir sus manos y luego frotárselas hasta los brazos, algunos se frotaron la nuca y espalda. El ritmo de los cantos iba en aumento pero bien coordinados.

Imagen 3

Mesa ceremonial y asistentes vestimenta de asistentes

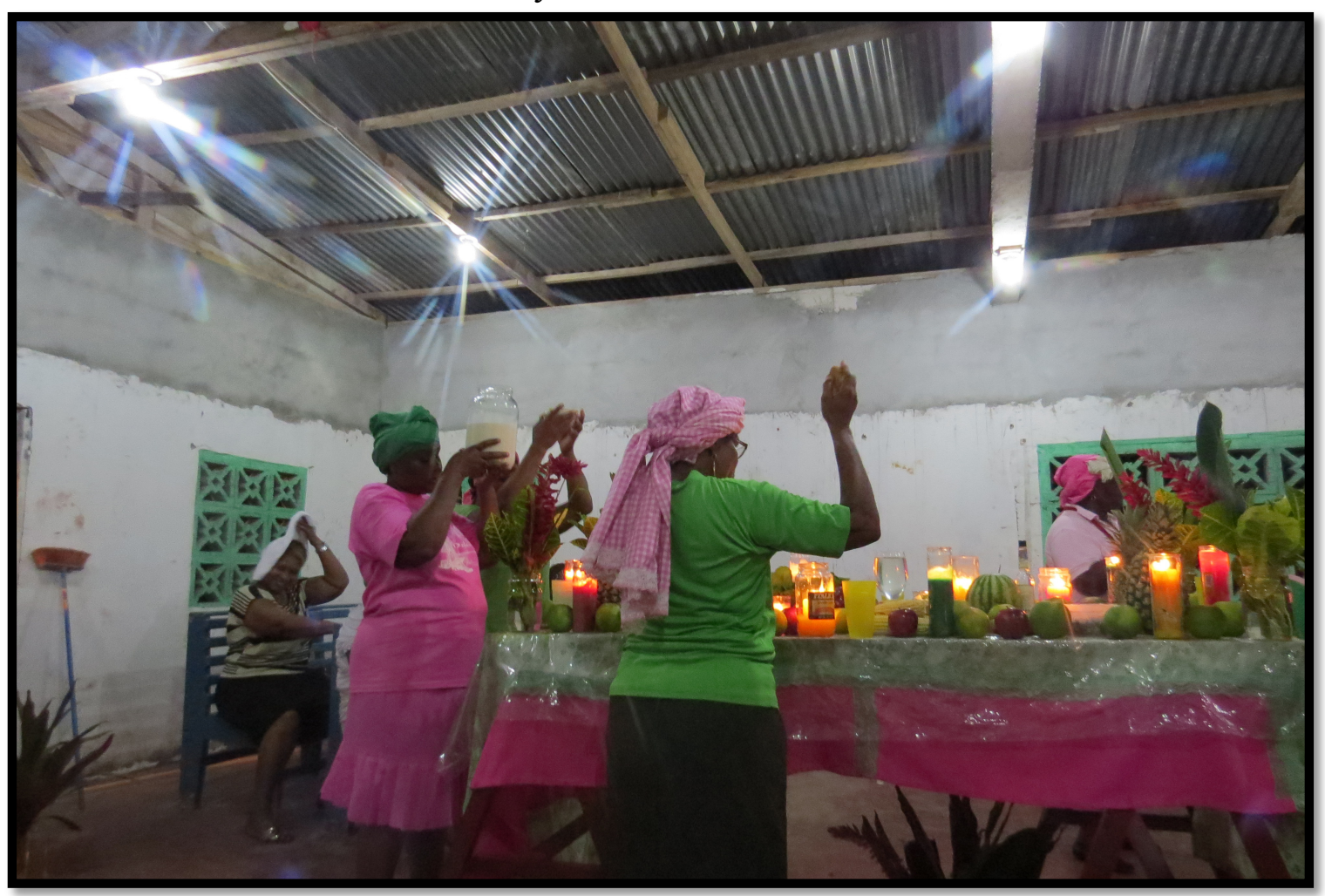

Fuente: Iglesia San Judas Tadeo

Las asistentes tomaron un frasco con plantas de los que adornaban la mesa y lo "presentaban" sobre la mesa bailando y cantando alrededor de la mesa. Después colocaron nuevamente los frascos en su lugar original y continuaron bailando y cantando. Empezaron a zapatear y a moverse hacia adelante y hacia atrás el cuerpo, los brazos acompañaban el movimiento en forma rítmica y ordenada. Una de ellas tomó un "báculo" que era de hierro y con una argolla en una de las puntas golpeaba el piso con el "báculo" con un movimiento del cuerpo hacia adelante y atrás acompañado de un golpe con el pie ${ }^{32}$. Se unió a ella otra de las conductoras y entre las dos golpeaban el piso con el "Báculo" mientras se movían alrededor de la mesa a un ritmo más rápido.

\footnotetext{
${ }^{32}$ Cuando es la vela de alguno de sus feligreses, el ataúd se debe pasar debajo de dos "Báculos" que se unen por la argolla. También se coloca sobre la puerta para evitar que entren malos espíritus.
} 
Figura 4

Báculo ceremonial

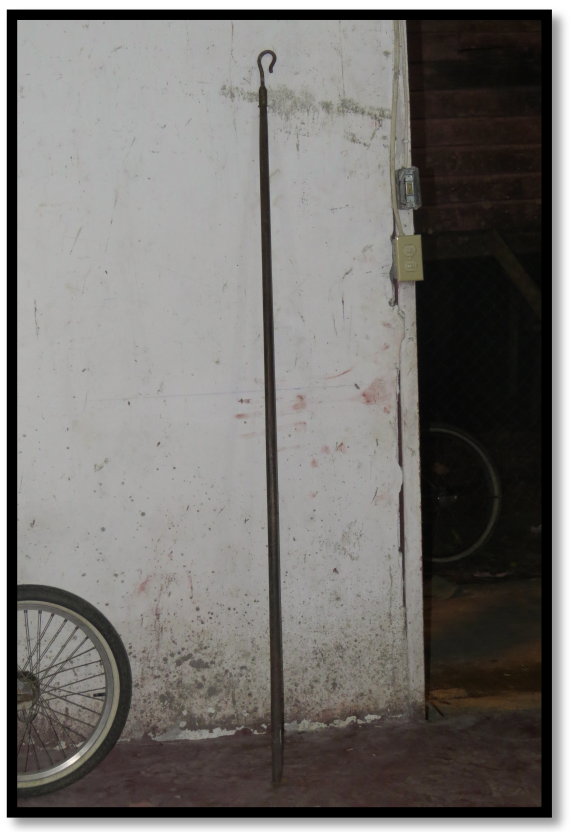

Fuente: Iglesia San Judas Tadeo.

Su canto fue sustituido por un sonido gutural que decía: "majéi, majéi, majéi", por parte de las dos que golpeaban con el "báculo". Después dejaron de moverse aunque continuaron golpeando el piso a un ritmo más rápido. Doña Diana se acercó a una de ellas y le amarró un cordón rojo alrededor de la cintura ${ }^{33}$ e inmediatamente la hermana empezó a quejarse. Sus movimientos y sonidos guturales aumentaron de ritmo hasta que de repente se detuvieron. Ambas se agacharon colocando sus manos sobre las piernas como para sostenerse. La del cordón rojo mantenía los ojos cerrados y fue atendida por la señora Diana que la frotaba con "Agua Florida" como para tratar de sacarla del "trance" en que se encontraba. Luego fue llevaba al altar donde empezó a rezar. Mientras rezaba la señora Diana le ayudaba a salir del estado en que se encontraba. Lo mismo sucedía con su acompañante con el "báculo" la cual era atendida por otra conductora que la frotaba en el pecho con "Agua Florida". Minutos después, las dos salieron de su "Trance" y los cantos continuaron. Casi al final de la actividad se nos pidió acercarnos a la mesa. Las mujeres invitadas que tenían la cabeza descubierta la cubrieron con un pañito. Se cantó un par de veces más y se pidió la intersección de San Judas Tadeo para el cumplimiento de una petición o deseo. Después se repartió un panecillo y un vaso con leche que tenían trozos de galleta soda en el fondo. En una mano un panecillo y en la otra el vaso con leche, ambas se

\footnotetext{
${ }^{33}$ El uso del cordón es obligatorio, dentro y fuera del templo, se usa como protección y para no caerse cuando se entra en "trance".
} 
levantaban como haciendo una ofrenda y luego de otros cantos se pidió tomar y comer la ofrenda. Después, los presentes se sentaron y una de las asistentes pasó con una canastita pidiendo una ofrenda económica. Al final, la misma persona se paró frente al altar y con la canastita en la mano dio gracias y pidió bendiciones para todos los que dieron o no dieron su ofrenda. Los panecillos y frutas que estaban en la mesa se repartieron entre los presentes".

En posterior conversación con las conductoras del culto, se menciona que a veces la posesión espiritual podía revelar un número de los chances ${ }^{34} \mathrm{o}$ alguna desgracia por venir a alguno de los feligreses. En ocasiones las revelaciones podrían verse en una de las candelas de la mesa. Como las "hermanas" celebraban el novenario, tenían que ayunar durante el día hasta después de tomar la leche con soda. Los grados de su iglesia son en orden de jerárquico: Cardenal, Patriarca, Obispo, Pastor y Diácono a un mismo nivel y evangelista. Por último, uno de los requisitos para ser Obispo es tener su propia Iglesia.

Lo que se puede resaltar de las "Iglesias Espirituales" de Panamá es que todas tienen un templo donde practican sus rituales. En el caso de Limón, ninguna de ellas lo tuvo.

\section{Relatos sobre la Pocomía en Limón}

En Limón, después de expulsiones y satanización del culto, los practicantes que quedaron continuaron congregándose en lugares "secretos" aunque buena parte de la población de la ciudad de Limón sabía dónde se reunían. Con el pasar del tiempo los lugares de reunión han sido consumidos por el crecimiento de la ciudad.

Se sabía de tres sitios de reunión: "Milla Uno", las montañas de Moín ${ }^{35}$ y Santa Rosa. "Milla Uno" fue el lugar donde fue apresado el pastor Davis. El nombre de "Milla Uno" se debe a que la distancia entre el muelle y ese sitio es de una milla.

A continuación se transcriben las experiencias de personas que conocieron el culto de la pocomía, algunos como invitados y otros como curiosos observadores desde una distancia "segura" según su relato. La transcripción de algunos de los entrevistados se realizó respetando el lenguaje coloquial expresado en español y en inglés.

\footnotetext{
${ }^{34}$ Los chances en Panamá es el equivalente a la venta de lotería de la Junta de Protección Social en Costa Rica.

${ }^{35}$ Así se les llamaba a las lomas que se encuentran entre Piuta y el Mirador de Moín.
} 
Joyce Sawyer, educadora pensionada ${ }^{36}$.

El lugar donde se reunían los pocomías era "Milla Uno". Siendo niña visité el lugar a pesar que mi madre me lo había prohibido. Llegué al lugar en horas de la noche, ellos se ponían algo en la frente, era como un aceite pero yo no dejé que me lo pusieran $^{37}$. Todos bailaban y emitían un sonido gutural, como bramando. Si usted no entiende su pensamiento podría confundir lo que hacen con la brujería. No vi ningún tipo de ritual de sangre, pero los pocomías creen en "pagarle a la tierra". "Lo único que no me gusta de ellos es cuando se desmayan, pero, tienen una coreografía muy bonita cuando bailan y cantan, eso sí me gustó.

Thelma Griffiths, ama de casa ${ }^{38}$.

Yo escuché de ellos cuando era pequeña. Ellos se reunían en San Juan, detrás de una iglesia que está ahí ahora ${ }^{39}$. Ahí había unos bambús y cerca pasaba un riachuelo. Era el año 1944 o 1945. Ellos ponían muchas candelas en el suelo y una manta blanca. En la manta ponían candelas y frutas y comida. Se vestían de blanco y usaban un pañuelo blanco en la cabeza, cantaban y hacían un sonido como hacen los chanchos. El que mandaba era un hombre, era jamaiquino y se llamaba Davis, había mujeres y a una le llamaban "Madda". Mi mamá no quería que yo fuera porque decían que mataban chiquitos y que eso era del diablo. Lo que le puedo decir es que ellos daban de comer, yo estaba pequeña y a veces tenía hambre y ellos me daban comida. Se reunían como a las cuatro de la tarde hasta las doce de la noche aunque yo nunca me quedé tan tarde. Ellos hablaban como en lenguas. La verdad es que mi amiga y yo íbamos solo para comer porque éramos muy pobres (Se ríe a carcajadas). Yo solo fui como unas dos veces y ellos se reunían en semana santa, el viernes santo.

Julieta Arce Benavides, conserje ${ }^{40}$.

Tenía como siete años cuando fui con una amiga a esa montaña en San Juan detrás de donde hoy hay una iglesia ${ }^{41}$. Era como el año 1961-1962. Yo me crie con negros y andaba de arriba pa abajo con ellos. Ese lugar era de nosotros porque mi mamá andaba con Rafael Ángel Vaglio Mata ${ }^{42}$ que era dueño de esos terrenos. Ellos tenían una casa vieja como un galerón con techo y sin paredes, una fogata en el centro y

${ }^{36}$ J. Sawyer, comunicación personal, 18 de abril de 2013.

${ }^{37}$ El aceite al que se hace referencia es el "Healing Oil" o "Aceite Curativo". Se utiliza en tratamiento contra dolores musculares, la artritis.

${ }^{38}$ T. Griffiths, comunicación personal, 18 de abril de 2013.

${ }^{39}$ El lugar indicado coincide con el sitio de reunión en "Milla Uno".

${ }^{40} \mathrm{~J}$. Arce, comunicación personal, 13 de julio de 2013.

${ }^{41}$ Coincide con "Milla Uno".

${ }^{42}$ Los Vaglio, inmigrantes italianos, eran comerciantes y propietarios de lo que hoy se conoce como Barrio Quinto, Limoncito y parte de San Juan. 
también ponían candelas. Empezaban a bailar antes de la media noche alrededor de la fogata. Cantaban y rezaban en inglés, eran cánticos religiosos También hacían sonidos raros, como aullando y se tiraban en el suelo como poseídos. Todos eran negros y hombres. Eran dirigidos por uno de ellos que vestía con una sotana gris y como con una boina del mismo color en la cabeza. Esperaban que eran las doce de la noche para empezar sus cosas. Yo los veía escondida entre los matorrales, una vez me vieron y tuve que salir corriendo de ahí.

Irma Watson, educadora pensionada ${ }^{43}$.

Yo vivía en barrio Roosevelt y cerca de donde hoy se encuentra la oficina de $\mathrm{AYA}^{44}$. Ahí vi en más de una ocasión a una señora vestida toda de blanco y con una túnica en la cabeza. Ahí se reunía con sus asistentes que eran mujeres pero solo ella se vestía así. No había una fogata y como era en la pura tarde la luz de la luna iluminaba lo suficiente. La señora bailaba y cantaba góspel. Los demás le hacían un círculo. Se tiraba al suelo como poseída por espíritus y emitía unos sonidos guturales extraños. Mucha gente se ponía a verla, gente de Limón. Solo supe que ellos venían de Almirante y después de un tiempo no volvieron a reunirse, no sé por qué.

George Watts, educador pensionado y reverendo de la Iglesia anglicana ${ }^{45}$.

Cuando era niño acompañaba a mi abuelita al Ejército de Salvación donde trabajaba. Era el año 1955. Pasábamos frente a un lugar ${ }^{46}$ donde ella me decía se reunían los de la pocomía. Mi abuela decía que se tiraban al piso y hacían mucho escándalo además que practicaban la brujería. En ese tiempo el lugar era de madera y uno podía "vinear" por los agujeros. Se podía ver las ofrendas sobre un altar pero no recuerdo haber visto candelas. La mayoría eran hombres aunque había una que otra mujer. Ellas se cubrían la cabeza con algo como un turbante o pañuelo. Después se prohibió esa actividad porque se decía "atentaba contra el orden público" por los escándalos que hacían".

Éste es el único relato que se tiene sobre la práctica de la pocomía en un sitio que no fuera al "aire libre". Como se relata, sus prácticas fueron prohibidas por escandalosos. El sitio no era un templo, era una casa que era alquilada para sus ritos.

\footnotetext{
${ }^{43}$ I. Watson, comunicación personal, 09 de octubre de 2014.

${ }^{44}$ Acueductos y Alcantarillados, institución estatal encargada del suministro del agua.

${ }^{45} \mathrm{G}$. Watts, comunicación personal, 12 de agosto de 2013.

${ }^{46}$ Omitimos el nombre del sitio para evitar "malos entendidos".
} 
Anita Calimore, educadora ${ }^{47}$.

Comentó que no sabía nada sobre la Pocomía hasta que se tocó el tema en una de sus entrevistas. Anita obtuvo la licenciatura en Teología de la Facultad de Filosofía y Letras de la Universidad Nacional (Costa Rica) con la presentación y defensa con éxito de la tesis titulada "Raíces de la Comunidad Negra Católica de Puerto Limón". Calimore entrevistó a veintisiete personas de la etnia negra y a un "blanco". Las preguntas aunque giraban en torno a la religiosidad no eran específicas lo que permitió abarcar muchos otros temas de índole social y político. Uno de los temas que se mencionaron fue sobre la Pocomía. Uno de los entrevistados fue el señor Daniel Plant, nacido en 1928. Él mencionó la llamada "secta de la Pocomía, que hoy en día les dicen los Panderetas, se cambió el panorama ${ }^{48}$.

Se ha cambiado ahora el panorama porque ellos predican el Evangelio igual como los negros lo practicaban en esos tiempos. Esto le decían el tal Pocomía, pero ahora actualmente es casi todo lo que es los Bautistas, lo que es todas esas religiones, ellos están ahora con lo que llamamos pandereta, es la misma cosa que la gente decía que los negros hacían sacrificios, eso no es cierto. El sacrificio es la misma cosa hoy en día que usted encuentra en los evangélicos, comienzan a predicar y pegan esos gritos, igual era la Pocomía. Porque la misma gente ahora actualmente que es de la pandereta ellos consiguen visiones igual que hoy día, ellos no dicen Pocomía, dicen "el evangelio bautista.

Calimore también entrevistó al famoso Marvin Wright Lindo, conocido como “calalú". Al señor "calalú" se le preguntó qué sabía sobre la secta practicada por los negros como la pocomía a lo cual respondió:

Yo lo que le puedo decir que la Pocomía que se practicaba en Limón era una secta beligerante, luchadora, no es como quieren decir que sacrificaban güilas ${ }^{49}$, no esos son cuentos. Era el grupo más beligerante en la lucha por resolver los problemas del negro. Esta secta iba a los distintos pueblos y se contactaban con las personas más identificadas, hacían un círculo cerrado, en lugar de llamarlo secta yo le diría es un grupo donde si lo hubiera dejado desarrollarse se hubiera tornado un partido político... Fueron perseguidos y echados de Costa Rica.

Por último, una nota de pie de página de la tesis se anotó lo siguiente: "Se dice que la iglesia Bautista Progresiva estuvo en manos de varios pastores entre ellos Mista Albriche

\footnotetext{
${ }^{47}$ A. Calimore, comunicación personal, 14 de abril de 2013.

${ }^{48}$ Se transcribe tal y como se escribió la cita original.

${ }^{49}$ Costarriqueñismo para llamar a las personas que están entre la niñez y la pubertad.
} 
después Mista Ryle, pero antes de ser Iglesia Bautista se practicaba ahí la Pocomía (secta Pocomía)" ${ }^{50}$.

\section{Conclusión}

El vínculo existente entre la práctica de la Pocomía en Limón y Bocas del Toro nos demuestra que existió un verdadero corredor cultural entre ambos países. En relación a las "Iglesias Espirituales" en Panamá todo parece indicar que la globalización y sus manifestaciones han pesado fuerte en los ritos originales de las iglesias. Algunas prácticas se han eliminado ya que, de acuerdo con sus seguidores, podrían ser confundidas con algo satánico. Una de esas prácticas es la del ayuno y rezo nocturno que antes era de más de veinticuatro horas, y donde a veces, una persona pasaba poseída hasta por siete días. De ésta manera se dio una transformación que eliminó el sincretismo existente al rechazar la herencia africana en sus rituales. Sin embargo, en sus prácticas se utiliza el góspel y se alaba a Dios. No utilizan fogatas ya que el culto es en un templo lo cual cambió el uso de la fogata por el de las velas. Las posesiones espirituales y el hablar en lenguas son comunes en sus actividades religiosas. Utilizan el Agua Florida ${ }^{51}$ para frotarse las manos, brazos, cuello y frente. También se esparcía en las esquinas del templo.

La pregunta que surge alrededor de estas iglesias de Panamá es, ¿por qué no fueron expulsados sus líderes y seguidores como sucedió en Limón? La respuesta que se puede brindar se relaciona con el hecho de que, las primeras iglesias, se encontraban en la zona del canal la cual era una verdadera colonia norteamericana. Las leyes norteamericanas del sur de los Estados Unidos se aplicaron en la zona del canal en donde el blanco norteamericano era el que mandaba. El estado panameño no tuvo ninguna injerencia es ese lugar. Ahí mandaban los norteamericanos. Bajo esas circunstancias se fueron desarrollando las "Iglesias Espirituales" alrededor de las cuales se aglomeraron los inmigrantes negros caribeños. Actualmente, forman parte de ellas todo tipo de etnias que pertenecen a los estratos más bajos de la sociedad.

Con lo que respecta a la pocomía de Limón, sus actividades fueron rechazadas por la población mestiza que era básicamente católica. Otro aspecto que jugó un papel negativo fue el "amarillismo" de los periodistas que propiciaron el rechazo de un credo religioso diferente al catolicismo.

\footnotetext{
${ }^{50}$ Calimore, "Raíces de la comunidad negra católica de Puerto Limón”, 123.

${ }^{51}$ Perfume hecho a base de ámbar, almizcle y benjuí. Tiene un aroma muy fuerte y agradable. Es usado para refrescar, para poner olor a las sábanas, como perfume y por algunos cultos como la santería y la pocomía en Panamá.
} 
El poder de la UFCo en la Limón no se compara con el poder de los norteamericanos en la zona del canal ${ }^{52}$. En Limón las autoridades policiales e instituciones del Estado existían y funcionaban de acuerdo a las leyes del país. Por esa razón fueron expulsados los líderes de la pocomía a diferencia de lo sucedido con sus iglesias hermanas de la zona del canal. Los pocomías de Limón nunca tuvieron un templo para sus prácticas. Todas sus actividades se realizaron en lugares alejados de la ciudad, al aire libre, en horas de la noche y alrededor de una fogata.

¿Qué pasó con los seguidores de la pocomía de Limón? De acuerdo con las entrevistas realizadas, todos terminaron formando parte de algún culto evangélico, aquellos que entre sus prácticas se encontraba la "posesión espiritual" y el "hablar en lenguas". Como lo dijo el señor Plant, esos cultos eran "los panderetas". Los panderetas" acogieron, sin saber, a los antiguos miembros de la pocomía.

La pocomía fue sin lugar a dudas el resultado de un sincretismo religioso. Surgió en Jamaica y llego a limón gracias a los trabajadores caribeños del ferrocarril. Sus actividades nunca fueron aceptadas por la población local y nacional. Incluso algunos miembros de los inmigrantes jamaiquinos pertenecientes a las religiones históricas establecidas en Limón criticaron las prácticas de la pocomía y a sus líderes. Es importante señalar que, al igual que en Panamá, los seguidores de la pocomía pertenecían a los estratos sociales más bajos de la población negra caribeña.

El surgimiento de los cultos en Panamá y Limón obedeció a situaciones socioculturales muy diferentes pero que acogieron a una población inmigrante caribeña explotada. Con lo que respecta a sus prácticas, ni en Panamá ni en Limón se encontró ningún indicio que identificara sus actividades con el rapto y sacrifico de niños o con algún rito de sangre.

Aunque se pretende estudiar otras manifestaciones culturales de los afrodescendientes en el continente americano para poder establecer algún vínculo con la pocomía o similitud en sus prácticas, se considera acertado y necesario decir que el Jumpy-Jumpy y la pocomía surgieron del resultado de un sincretismo religiosos africano y evangélico durante el avivamiento cristiano en Jamaica y que se desarrollaron en forma diferente en ambos países. Otro aspecto importante es que los practicantes de la pocomía no utilizaron tambores para sus ritos.

Los principios cristianos de la pocomía traen intrínseco prácticas cristianas, pero, no se estableció ningún principio filantrópico entre sus actividades. Por otro lado, no existe una unión entre las llamadas "iglesias espirituales" en Panamá, a diferencia de las logias que, sin importar a cual pertenecía la persona, podían participar por invitación en sus

\footnotetext{
${ }^{52}$ Sin embargo, la UFCo propició el odio entre sus trabajadores mestizos y negros caribeños para evitar que se unieran.
} 
actividades. En el caso de las "Iglesias Espirituales" de Panamá, para lograr el grado de obispo, se necesita tener su propio templo lo cual podría impulsar la separación.

En Limón por las circunstancias de rechazo y satanización de la pocomía, provocó que sus integrantes se alejaran de la sociedad estableciendo lazos de unión y ayuda mutua, únicamente, entre sus miembros.

\section{Bibliografía}

Armstrong, Sydney E. A Religious History of the American People. New Haven y Londres: Yale University Press, 1972.

Bryce-Laporte, Roy Simon. "Religión Folklórica y Negros Antillanos en la Zona del Canal de Panamá". Revista Nacional de Cultura 5 (1976): 523-548.

Calimore Forbes, Anita. "Raíces de la comunidad negra católica de Puerto Limón". Tesis de Licenciada en Teología, Universidad Nacional de Costa Rica, 1993.

Chomsky, Avi. "Afro-Jamaican traditions and labor organizing on United Fruit Company plantations in Costa Rica, 1910". Journal of Social History 28, no. 4 (1995): 837855.

Diario de Costa Rica 1936.

Fallas, Carlos. Mamita Yunai.San José: Editorial Costa Rica, 2008.

Fallas, Carlos. Mamita Yunai.San José: Editorial Costa Rica, 2008.

Harpelle, Ronald N. "Ethnicity, Religion and Repression: The Denial of African Heritage in Costa Rica". Canadian Journal of History 29, no. 1 (1994): 95-112.

Holland, Clifton L. ed. Enciclopedia de grupos religiosos en América Latina y el Caribe: Religión en Jamaica. Traducido por Carmen Luna Hernández. San José: PROLADES, 2011 [citado el 26 de marzo del 2016]): disponible en http://www.prolades.com/encyclopedia/countries/spanish/rel jamaica09spn.pdf

La Voz del Atlántico 1936.

Márquez, Concepción. "Myalismo y Obeah: Sincretismo y Poder". Kálathos: Revista Transdisciplinaria Metro-Inter 6, no. 2 (2012-2013 [citado el 26 de marzo del 2016]): disponible

en http://kalathos.metro.inter.edu/kalathos mag/publications/archivo5 vol6_no2.pdf

Martín, Gustavo. "Magia, religión y poder Los cultos afroamericanos", Nueva Sociedad 82 (marzo-abril 1986 [citado el 12 de abril del 2015]): disponible en http://nuso.org/media/articles/downloads/1382_1.pdf

Martínez Esquivel, Ricardo. "Sociabilidades modernas: sociedades fraternales secretas en el Caribe costarricense a finales del siglo XIX". MEMORIAS. Revista digital de Historia y Arqueología desde el Caribe colombiano 7, no. 12. (2010 [citado el 14 de agosto de 2015]): disponible en http://rcientificas.uninorte.edu.co/index.php/memorias/article/viewArticle/516/5109 
Nitoburg, Eduard. Los africanos en el nuevo mundo. El elemento negroide en la formación de las nacionalidades en América. Traducido por Pavel Boyko. Moscú: Progreso, 1991.

Anexo 1

Desarrollo del Gran Avivamiento Evangélico jamaiquino en Limón (Costa Rica) y Bocas del Toro (Panamá)

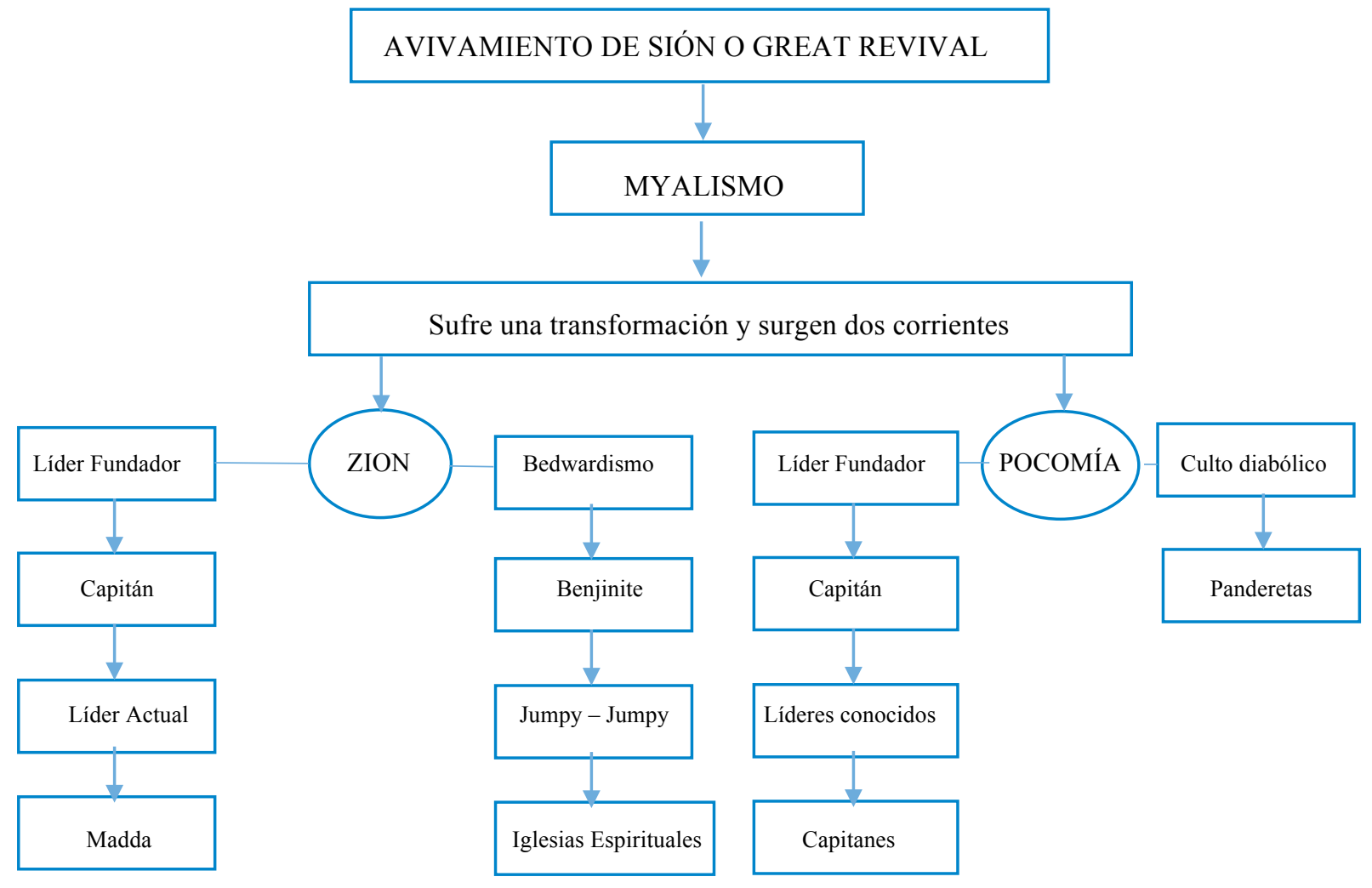

